06,13

\title{
Влияние ориентации кремниевой подложки с буферным подслоем карбида кремния на диэлектрические и полярные свойства пленок нитрида алюминия
}

(C) О.Н. Сергеева ${ }^{1,2}$, А.В. Солнышкин ${ }^{1,2}$, Д.А. Киселев 2,3 , Т.С. Ильина ${ }^{3}$, С.А. Кукушкин ${ }^{2,4}$, Ш.Ш. Шарофидинов ${ }^{2,5}$, Е.Ю. Каптелов ${ }^{2,5}$, И.П. Пронин ${ }^{2,5}$

${ }^{1}$ Тверской государственный университет,

Тверь, Россия

${ }^{2}$ Российский государственный педагогический университет им. А.И. Герцена,

Санкт-Петербург, Россия

${ }^{3}$ Национальный исследовательский технологический университет „МИСиС“,

Москва, Россия

${ }^{4}$ Институт проблем машиноведения РАН,

Санкт-Петербург, Россия

${ }^{5}$ Физико-технический институт им. А.Ф. Иофрфе,

Санкт-Петербург, Россия

E-mail: o_n_sergeeva@mail.ru

Поступила в Редакцию 16 июля 2019 г.

В окончательной редакции 16 июля 2019 г.

Принята к публикации 25 июля 2019 г.

Исследуются диэлектрические и полярные свойства тонких пленок нитрида алюминия (AlN), эпитаксиально выращенных на различно ориентированных кремниевых подложках $p$-типа проводимости с буферным подслоем карбида кремния $(\mathrm{SiC})$, а также на вицинальных плоскостях. По результатам исследований полярных свойств двумя независимыми методами - динамического пироэффекта и силовой микроскопии пьезоотклика, показано, что использование буферного слоя $\mathrm{SiC}$ существенно улучшает полярные свойства тонких слоев нитрида алюминия.

Ключевые слова: подложки кремния с различной ориентацией, вицинальные поверхности, буферный слой карбида кремния, тонкие слои нитрида алюминия, пироэлектрический эффект, пьезоэлектрический эффект.

DOI: $10.21883 /$ FTT.2019.12.48558.22ks

\section{1. Введение}

Оригинальный метод твердофазного замещения атомов кремния атомами углерода на $\langle 111\rangle$-ориентированной кремниевой $(\mathrm{Si})$ подложке позволяет выращивать $\langle 111\rangle$-эпитаксиальные нанослои карбида кремния $(\mathrm{SiC})$ толщиной $60-100 \mathrm{~nm}$, несмотря на то, что различие в параметрах их кристаллических решеток составляет $\sim 20 \%$ [1-2]. Благодаря наличию буферного слоя $\mathrm{SiC}$ появилась возможность выращивать на $\mathrm{SiC} /(111) \mathrm{Si}$ подложках высококачественные эпитаксиальные слои широкозонных полупроводников- нитридов галлия $(\mathrm{GaN})$ и алюминия $(\mathrm{AlN})$, а также другие слои на их основе. Это связано с тем, что параметры их решеток отличаются менее чем на $1 \%$ от соответствующих параметров решетки $\mathrm{SiC}$ [3-5]. Таким образом выращенные гетероструктуры позволяют повысить эффективность созданных на их основе оптоэлектронных устройств, в том числе, лазерных фотодиодов, работающих в видимой и ультрафиолетовой областях длин волн [6-8].

Эпитаксиальный рост слоев $\mathrm{GaN}$ и $\mathrm{AlN}$ на $\mathrm{SiC} /(111) \mathrm{Si}$ подложке происходит в направлении их полярной $\langle 0002\rangle$-гексагональной оси. Поэтому такие слои облада- ют значительной спонтанной поляризацией [9] и внутренним полем, что отрицательно сказывается на работе светоизлучающих устройств. Поэтому в последнее время предпринимаются попытки получения тонких пленок нитридов, в которых ростовая полярная ось была бы наклонена как можно ближе к поверхности подложки, для чего используются кремниевые пластины с отличной от $\langle 111\rangle$ ориентации [10-12].

Вместе с тем, полярные слои нитридов обладают пьезоэлектрическими и пироэлектрическими свойствами, благодаря чему являются перспективными материалами для микроэлектромеханики (МЭМС) [13] и инфракрасной (ИК) техники [14]. Исследования полярных свойств тонкопленочных широкозонных полупроводников показали, что к числу наилучших пьезоэлектрических материалов относятся тонкие слои $\mathrm{AlN}$, характеризующиеся сочетанием высоких значений электромеханических коэффициентов, высокой теплопроводности и низкой электропроводности [15-20]. Однако в большинстве своем исследуемые пленки AIN представляют собой поликристаллические (текстурированные) слои, пьезоэлектрические свойства которых отличаются, как правило, в худшую сторону от кристаллически более совершенных 

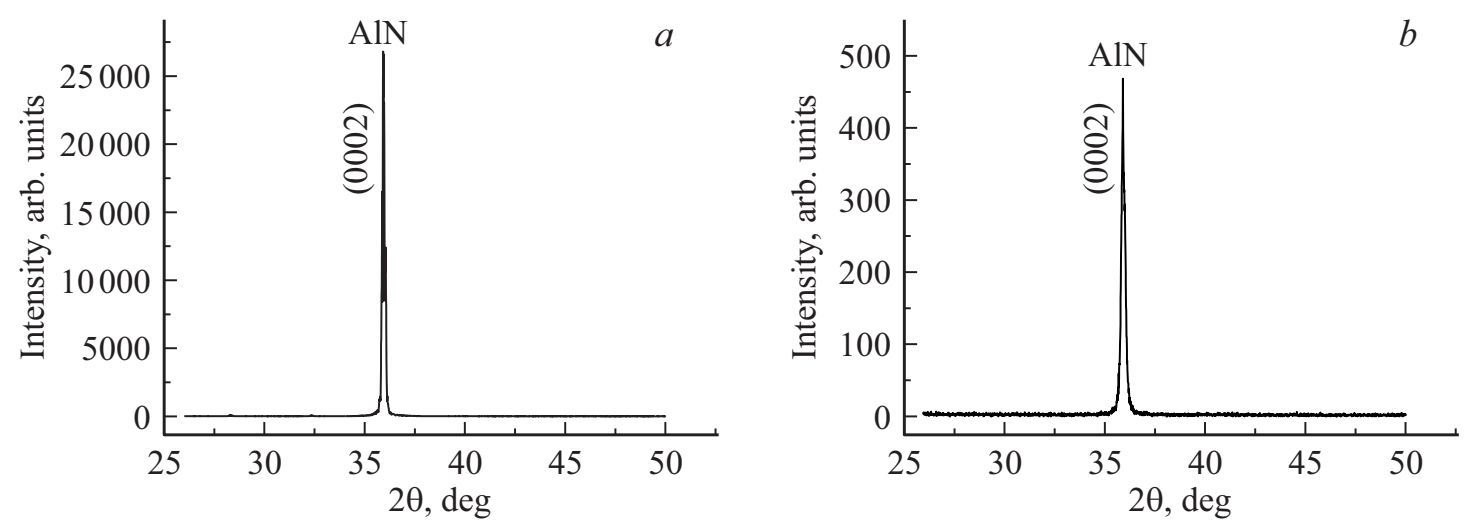

Рис. 1. Дифрактограммы тонких слоев $\mathrm{AlN}$, выращенных на подложках: $\mathrm{SiC} /(111) \mathrm{Si}(a)$ и $\mathrm{SiC} /(100) \mathrm{Si}(b)$.

эпитаксиальных пленок. Поэтому можно ожидать, что совершенствование технологии их роста, позволяющее уменьшить остаточную деформацию и растрескивание и улучшить качество поверхности, позволит выращивать пленки с максимальными пьезо- и пироэлектрическими параметрами. В этой связи целью настоящей работы являлось исследование полярных свойств тонких слоев $\mathrm{AlN}$, сформированных как на вицинальных $\mathrm{SiC} /(111) \mathrm{Si}$ подложках, так и на кремниевых (100) и (110) подложках с буферным слоем SiC.

\section{2. Объекты и методы исследования}

Слои AlN толщиной $1-2 \mu \mathrm{m}$ были выращены методом гибрид-хлоридной эпитаксии на подложках $\mathrm{SiC} / \mathrm{Si}$. Наноразмерный кристаллический слой карбида кремния $(50-80 \mathrm{~nm})$ получен методом замещения атомов кремния атомами углерода, разработанным в работе [1]. Карбид кремния осаждался на кремниевые подложки, p-типа проводимости, легированные атомами бора. Рост пленок $\mathrm{SiC}$ осуществлялся на поверхностях подложек $\mathrm{Si}(100),(110),(111)$, а так же и вицинальных поверхностях (100), (110) и (111), отклоненных от этих базовых ориентаций на $2-10^{\circ}$.

Для проведения электрофизических измерений на поверхность AlN наносился массив платиновых контактных площадок размером $1 \times 1 \mathrm{~mm}$. В качестве нижнего электрода использовался серебряный контакт, сформированный на свежем кремниевом сколе.

Кристаллическая структура тонких слоев исследовалась с помощью дифрактометра ДРОН-7. Микроструктура и морфология поверхности пленок изучалась методом сканирующей электронной (EVO-40, Zeiss) и атомно-силовой микроскопии (Ntegra Prima, NT-MDT). Локальные пьезоэлектрические характеристики пленок AIN изучались методом силовой микроскопии пьезоотклика (СМП) на сканирующем зондовом микроскопе MFP-3D (Asylum Research). В эксперименте по определению значений эффективного пьезоэлектрического коэффициента $\left(d_{33}\right)$ переменное напряжение амплиту- дой $1-8 \mathrm{~V}$ и частотой $50 \mathrm{kHz}$ подавалось на проводящий кантилевер марки NSG10/Pt (Tipsnano), что значительно меньше контактной резонансной частоты системы „зонд-образец“ $(\sim 800 \mathrm{kHz})$. Исследования (набор статистики) проводились в трех-четырех различных областях тонкопленочных образцов. Пироэлектрические свойства изучались динамическим методом неразрушающего контроля полярного состояния. Использовался прямоугольно модулированный в диапазоне частот $10 \mathrm{~Hz}-10 \mathrm{kHz}$ тепловой поток, источником которого являлось лазерное излучение с длиной волны $980 \mathrm{~nm}$. Контроль диэлектрического состояния слоев AlN производился с помощью измерителя иммитанca E7-20.

\section{3. Экспериментальные результаты}

Характер рентгенографических спектров тонких слоев AlN, выращенных на кремниевых подложках разной ориентации существенно различается по интенсивности рефлекса (0002), отвечающего гексагональной оси (рис. 1). Рефлекс большой интенсивности, представленный на рис. 1, $a$, отвечает гексагональной оси моноблочного слоя $\mathrm{AlN}$, сформированного на $\mathrm{SiC} /(111) \mathrm{Si}$ подложке. Полуполярные слои, выращенные на вицинальных поверхностях (100) и (110) кремниевых подложек, характеризовались ростовой текстурой вдоль гексагональной оси, наклоненной к плоскости подложки. В частности, на вицинальной поверхности (100) $\mathrm{Si}$, отклоненной на $4^{\circ}(100)$ величина этого угла составляла $\sim 54^{\circ} 44^{\prime}$, что полностью соответствовало модели роста $\mathrm{AlN}$, рассмотренной в работе [21]. Слабый по интенсивности рефлекс (0002), представленный на дифрактограмме на рис. $1, b$, свидетельствует о наличии незначительных включений кристаллитов AlN, ростовая ось „,“ у которых была ориентирована нормально к плоскости подложки.

Рис. 2, $a$ отражает спектральные зависимости диэлектрической проницаемости тонких пленок AlN, выращенных на подложках с различной ориентацией кремния. По характеру этих данных можно сделать вывод, что 

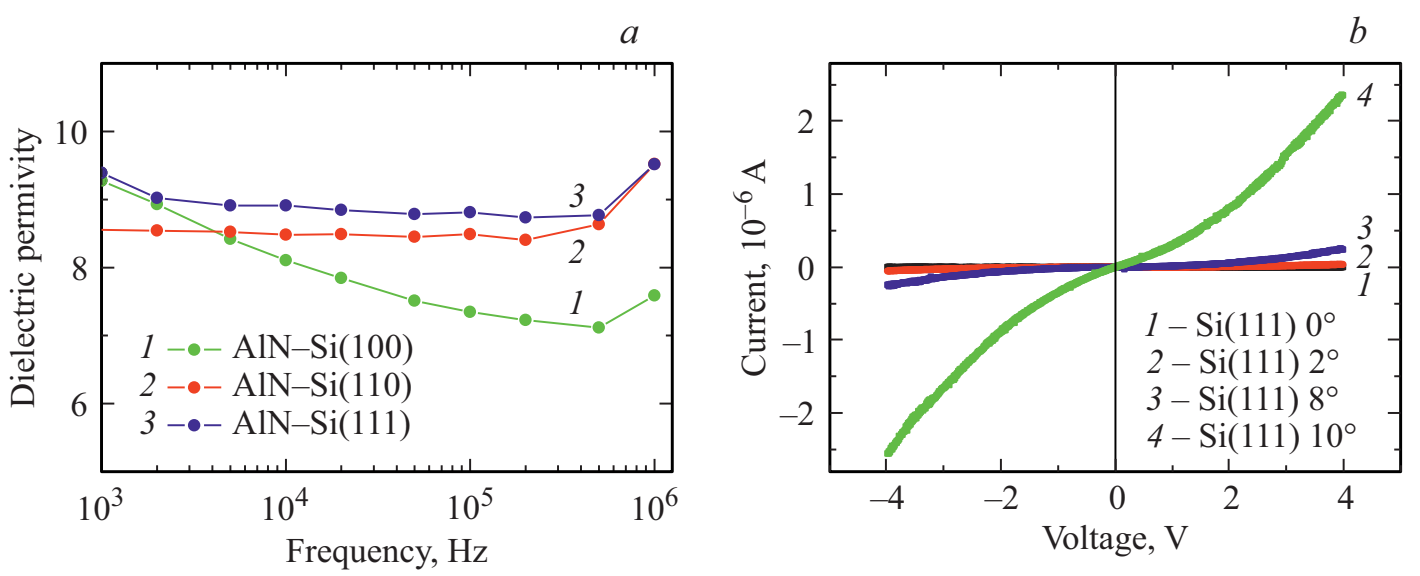

Рис. 2. Частотные зависимости диэлектрической проницаемости тонких слоев $\mathrm{AlN}$, выращенных на подложках $\mathrm{SiC} / \mathrm{Si}$ различной ориентации $(a)$ и вольт-амперные характеристики слоев $\mathrm{AlN}$, выращенных на вицинальных плоскостях $\mathrm{SiC} /(111) \mathrm{Si}$ подложек при различных углах отклонения $(b)$.
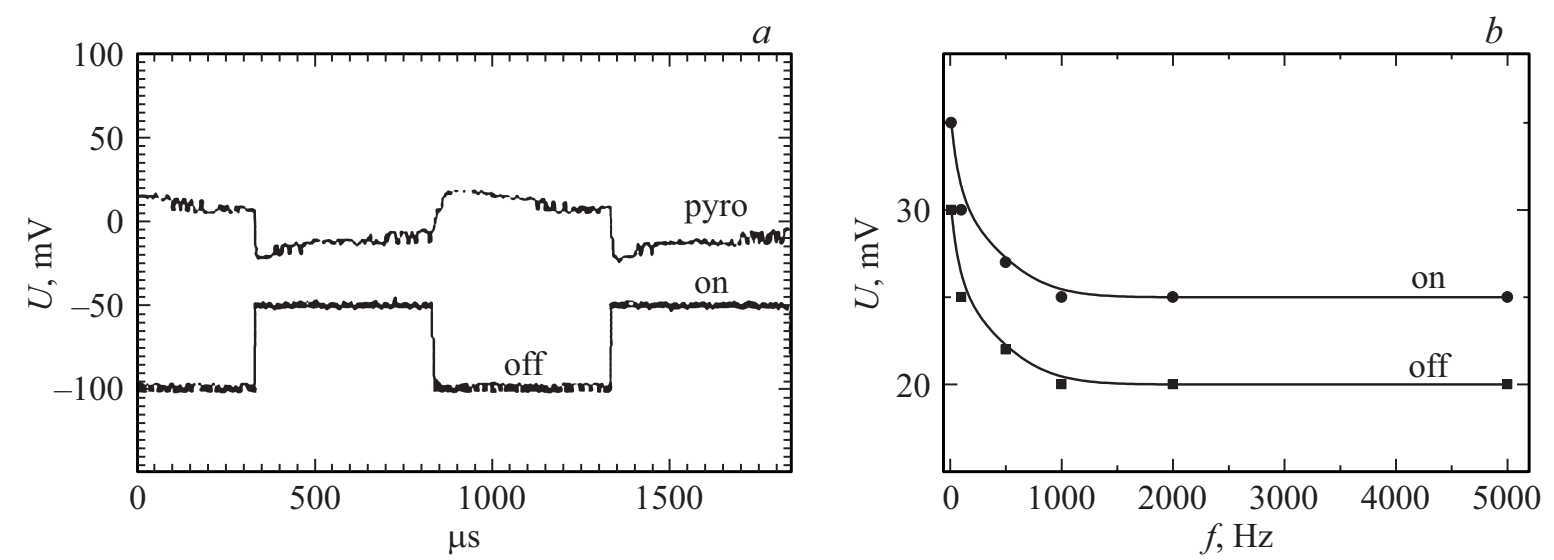

Рис. 3. Типичная форма пироотклика тонкого слоя $\mathrm{AlN}(1)$ и модулированного теплового потока $(2)(a)$ и частотные зависимости пироотклика $(b)$.

наилучшими диэлектрическими свойствами обладали пленки, выращенные на (111) и (110) кремниевых подложках, в которых отсутствовала дисперсия диэлектрической проницаемости. Характер вольт-амперных зависимостей свидетельствует о высокой электрической прочности пленок, изготовленных на кремнии основных кристаллографических направлений в диапазоне полей $0-100 \mathrm{kV} / \mathrm{cm}$ (рис. 2, $b$, кривая 1). Однако с ростом угла отклонения от базовой плоскости (на вицинальных плоскостях) увеличивается проводимость образцов и проявляется нелинейность вольт-амперных характеристик (рис. 2, $b$, кривые 2-4). Это можно связать с увеличением числа проводящих каналов в результате разориентации ростовых зерен и повышения концентрации межкристаллических границ.

При облучении исследуемых пленок модулированным тепловым излучением возникал биполярный электрический отклик, который изменял форму и величину с ростом частоты, что позволило нам сделать утверждение о его пироэлектрической природе (рис. 3). Типичная форма пироотклика пленок нитрида алюминия приведе- на на рис. 3, $a$, и произведен расчет пироэлектрических коэффициентов по формуле

$$
\gamma=\frac{2 U \rho c d}{W \eta R}
$$

где $2 U$ - сумма амплитуд сигнала пироотклика (нагрев/охлаждение), $\rho$ - плотность слоя $\mathrm{AlN}, c-$ удель-

Пироэлектрические коэффициенты тонких слоев AlN, выращенных на кремниевых подложках различной ориентации и вицинальных поверхностях

\begin{tabular}{l|c}
\hline \multicolumn{1}{c|}{ Структура } & $\gamma, 10^{-9} \mathrm{C} / \mathrm{cm}^{2} \cdot \mathrm{K}$ \\
\hline $\mathrm{AlN} / \mathrm{SiC} / \mathrm{Si}(100)$ & 0.9 \\
$\mathrm{AlN} / \mathrm{SiC} / \mathrm{Si}(100) 4^{\circ}$ & 0.8 \\
$\mathrm{AlN} / \mathrm{SiC} / \mathrm{Si}(110)$ & 0.9 \\
$\mathrm{AlN} / \mathrm{SiC} / \mathrm{Si}(110) 6^{\circ}$ & 0.8 \\
$\mathrm{AlN} / \mathrm{SiC} / \mathrm{Si}(111)$ & 2.0 \\
$\mathrm{AlN} / \mathrm{SiC} / \mathrm{Si}(111) 2^{\circ}$ & 1.3 \\
$\mathrm{AlN} / \mathrm{SiC} / \mathrm{Si}(111) 8^{\circ}$ & 1.2 \\
$\mathrm{AlN} / \mathrm{SiC} / \mathrm{Si}(111) 10^{\circ}$ & 1.5
\end{tabular}




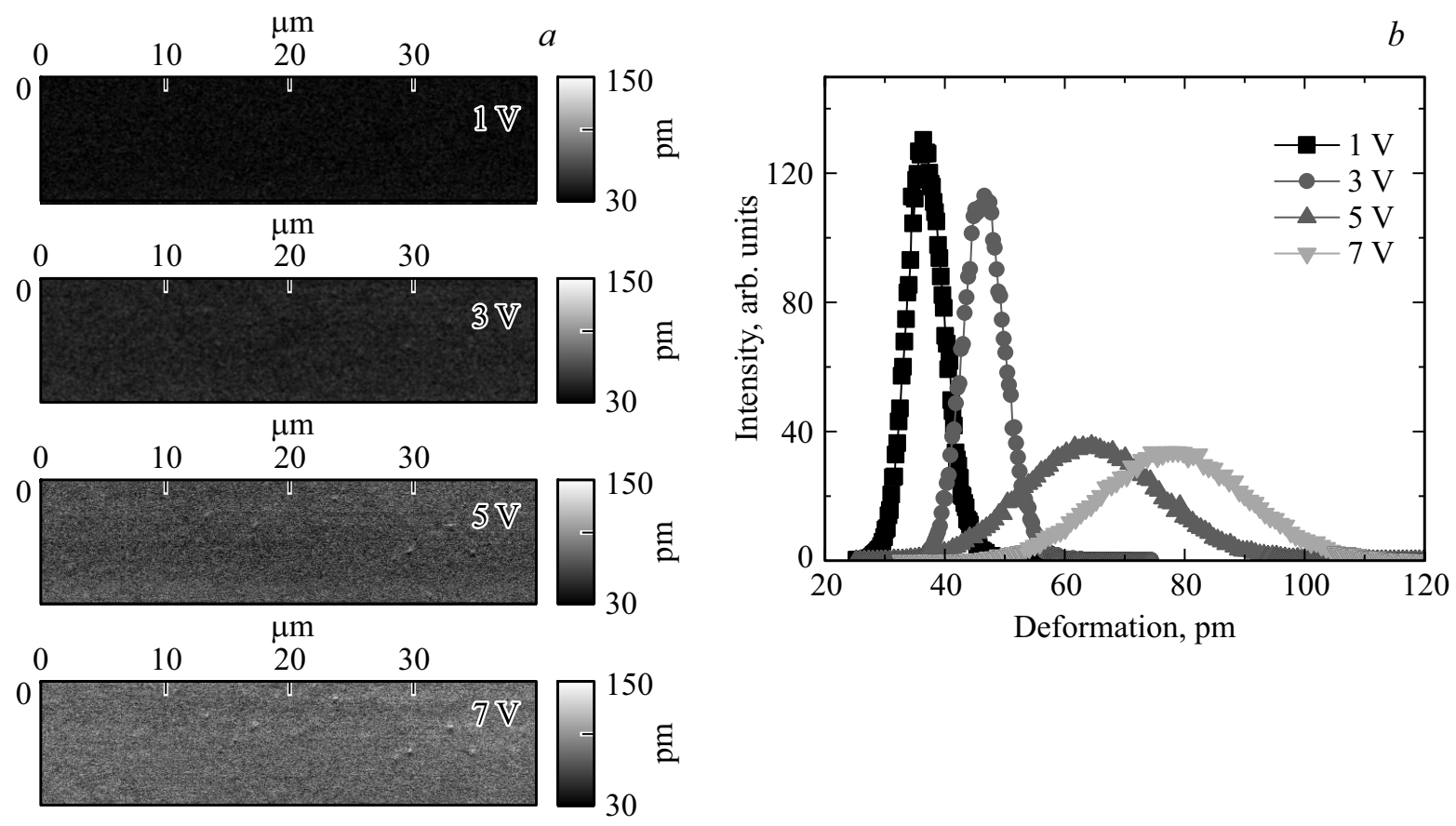

Рис. 4. ПСМ-изображения сигнала пьезоотклика под действием переменного напряжения различной величины $(a)$ и гистограммы распределения амплитуды сигнала пьезоотклика $(b)$.
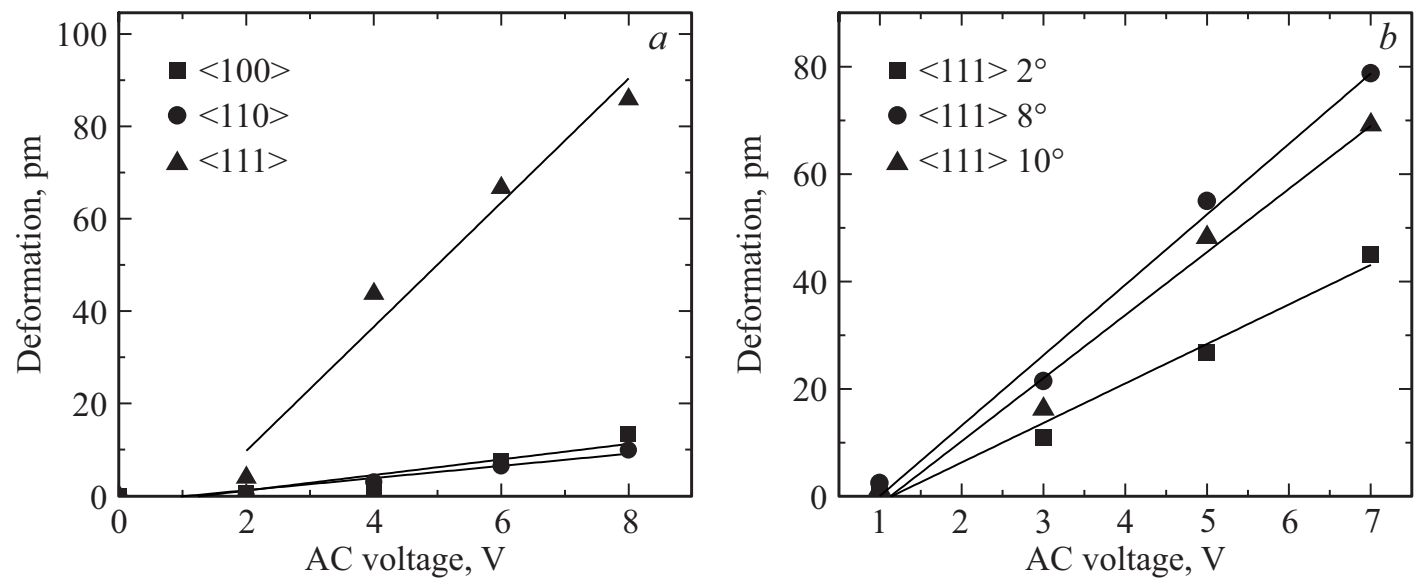

Рис. 5. Зависимости средней амплитуды пьезоотклика от приложенного напряжения для тонких слоев AlN, выращенных: $a)$ на подложках кремния различной ориентации с буферным слоем $\mathrm{SiC}$ и $b$ ) на вицинальных поверхностях $\mathrm{SiC} /(111) \mathrm{Si}$ при различных углах отклонения.

ная теплоемкость, $d-$ толщина слоя, $W-$ мощность падающего излучения, $\eta-$ коэффициент оптического поглощения платинового электрода, $R-$ входное сопротивление усилителя. Рассчитанные значения приведены в таблице.

Как видно из таблицы, наибольшая величина пирокоэффициента наблюдалась в тонких слоях нитрида алюминия, сформированных на (111)-подложке кремния, а почти вдвое меньшие величины отвечали слоям AlN, выращенных на (100) и (110) подложках. В пленках AlN, выращенных на вицинальных плоскостях, с ростом угла отклонения от направления $\langle 111\rangle \mathrm{Si}$ подложки величина пирокоэффициента также уменьшалась.
Для определения пьезоэлектрических коэффициентов проводилось измерение зависимости амплитуды локальной деформации образцов тонких слоев AlN под действием электрического поля, созданного напряжением, приложенным между кантилевером и $\mathrm{Si}$-подложками различных ориентаций. На рис. 4, $a$ представлены изображения амплитуды сигнала пьезоотклика тонкого слоя AlN, выращенного на вицинальной поверхности $\mathrm{SiC} / \mathrm{Si}(111)$ с углом отклонения $2^{\circ}$ под действием переменного напряжения амплитудой $1 \mathrm{~V}, 3 \mathrm{~V}, 5 \mathrm{~V}$ и $7 \mathrm{~V}$, соответственно. Хорошо видно, что контраст амплитуды пьезосигнала возрастает с ростом величины переменного напряжения, подаваемого на проводящий кантилевер. 
На рис. $4, b$ показаны гистограммы распределения сигнала амплитуды пьезоотклика для СМП изображений, полученных при регистрирующем переменном напряжении с амплитудой $1-7 \mathrm{~V}$ (рис. 4, $a$ ). Среднее значение амплитуды сигнала пьезоотклика, определенное из гистограмм, является мерой деформации пленки индуцированной приложенным напряжением. Аналогичная процедура была выполнена для всех исследуемых в работе образцов AlN.

На рис. 5, а приведены зависимости средней амплитуды пьезоотклика от приложенного напряжения для тонких слоев, выращенных на кремниевых подложках разной ориентации. Аппроксимируя полученные зависимости линейной функцией, по наклону кривой можно определить значение эффективного пьезоэлектрического модуля $d_{33}$, который находится из выражения

$$
d_{33}=\frac{A}{V_{A C}}
$$

где $A$ - амплитуда пьезосигнала (pm), $V_{A C}$ - значения амплитуды переменного напряжения (V).

Таким образом определенные величины $d_{33}$ для тонких слоев AlN, осажденных на (111), (110) и (100) кремниевых подложках, имели значения $\sim 13.4 \mathrm{pm} / \mathrm{V}$, $1.7 \mathrm{pm} / \mathrm{V}$ и $1.3 \mathrm{pm} / \mathrm{V}$ соответственно. Эти результаты показывают, что величина пьезоотклика резко уменьшается (в 5-10 раз) при выращивании полуполярных слоев AlN по сравнению с величиной сигнала полярных слоев.

Аналогичные измерения были проведены на тонких слоях AlN, выращенных на вицинальных поверхностях $\mathrm{SiC} / \mathrm{Si}(111)$ подложек с углом отклонения от плоскости, равным 2, 8 и 10 градусов (рис. 5,b). Полученные величины изменялись в диапазоне от минимального значения $d_{33} \sim 7.4 \mathrm{pm} / \mathrm{V}$ при угле отклонения $2^{\circ}$, до максимального значения $d_{33} \sim 13.1 \mathrm{pm} / \mathrm{V}$ при угле отклонения $8^{\circ}$. С учетом величины $d_{33} \sim 13,4 \mathrm{pm} / \mathrm{V}$, полученной на структуре $\mathrm{AlN} / \mathrm{SiC} / \mathrm{Si}(111)$ (рис. 5,a), явной закономерности в изменении эффективного пьезомодуля на данный момент не прослеживается. Вместе с тем, экспериментально полученные значения $d_{33}$ превышают значения, приведенные в литературе [22-24]. Этот факт свидетельствует о том, что использование буферного слоя $\mathrm{SiC}$ способствует формированию на кремниевой подложке высококачественных полярных слоев AlN.

На основании проведенных исследований можно сделать следующие выводы:

1. Наблюдается определенная корреляция в результатах измерения пьезоэлектрических и пироэлектрических свойств. Максимальные значения пиро- и пьезоэлектрических коэффициентов получены в полярных структурах $\mathrm{AlN} / \mathrm{SiC} / \mathrm{Si}(111)$, см. рис. 5 и таблицу.

2. Слои AlN, выращенные на вицинальных поверхностях кремниевых подложек, характеризуются меньшими значениями пироотклика. Несмотря на то, что измеренные значения пироотклика на полуполярных слоях AIN примерно в два раза меньше, чем в полярных слоях, их уменьшение не столь значительно, как изменения значений пьезомодуля $d_{33}$.

3. Полученные результаты свидетельствуют о перспективности использования полярных структур $\mathrm{AlN} / \mathrm{SiC} / \mathrm{Si}(111)$ для создания на их основе эффективных МЭМС преобразователей и устройств ИК-техники.

\section{Финансирование работы}

Работа выполнена при частичной поддержке в рамках проектной части гос. задания, проект № 16.2811.2017/4.6.

Исследования методами сканирующей зондовой микроскопии выполнены при финансовой поддержке Министерства науки и высшего образования РФ на оборудовании ЦКП „Материаловедение и металлургия“ НИТУ „МИСиС“ (проект № 11.9706.2017/7.8).

\section{Конфликт интересов}

Авторы заявляют, что у них нет конфликта интересов.

\section{Список литературы}

[1] С.А. Кукушкин, А.В. Осипов. ФТТ 50, 1188 (2008).

[2] S.A. Kukushkin, A.V. Osipov. J. Phys. D 47, 313001 (2014).

[3] В.Н. Бессолов, Ю.В. Жиляев, Е.В. Коненкова, Л.М. Сорокин, Н.А. Феоктистов, Ш.Ш. Шарофидинов, М.П. Щеглов, С.А. Кукушкин, Л.И. Метс, А.В. Осипов. Письма в ЖТФ 36, 17 (2010).

[4] В.Н. Бессолов, Ю.В. Жиляев, Е.В. Коненкова, Л.М. Сорокин, Н.А. Феоктистов, Ш.Ш. Шарофидинов, М.П. Щеглов, С.А. Кукушкин, Л.И. Метс, А.В. Осипов. Опт. журн. 78, 23 (2011).

[5] Ш.Ш. Шарофидинов, С.А. Кукушкин, А.В. Редьков, А.С. Гращенко, А.В. Осипов. Письма в ЖТФ 45, 24 (2019).

[6] S. Nakamura, T. Mukai, M. Senoh. Appl. Phys. Lett. 64, 1687 (1994).

[7] S. Guha, N.A. Bojarczuk. Appl. Phys. Lett. 72, 415 (1998).

[8] A. Dadgar, C. Hums, A. Diez, J. Blasing, A. Krost. J. Cryst. Growth. 297, 279 (2006).

[9] С.Ю. Давыдов. ФТТ 51, 164 (2009).

[10] Y. Abe, T. Isshiki, S. Suzuki, A. Yoshida, H. Ohishi, H. Nakanishi. Mater. Sci. Forum 600, 1281 (2009).

[11] В.Н. Бессолов, Ю.В. Жиляев, Е.В. Коненкова, Н.К. Полетаев, Ш.Ш. Шарофидинов, М.П. Щеглов. Письма в ЖТФ 38, 21 (2012).

[12] Duc V. Dinh, S. Presa, M. Akhter, P.P. Maaskant, B. Corbett, P. Parbroo. Semiconductor Sci. Technology 30, 125007 (2015).

[13] P. Muralt. Rep. Progr. Phys. 64, 1339 (2001).

[14] S. Trolier-McKinstry, P. Muralt. J. Electroceram. 12, 7 (2004).

[15] A. Artieda, M. Barbieri, C.S. Sandu, P. Muralt. J. Appl. Phys. 105, 024504 (2009).

[16] K. Tonisch, V. Cimalla, Ch. Foerster, H. Romanus, O. Ambacher, D. Dontsov. Sensors Actuators A 132, 658 (2006).

[17] P. Muralt. J. Am. Ceram. Soc. 91, 1385 (2008).

[18] L. Natta, V.M. Mastronardi, F. Guido, L. Algieri, S. Puce, F. Pisano, F. Rizzi, R. Pulli, A. Qualtieri, M. De Vittorio. Sci. Rep. 9, 8392 (2019). 
[19] O.N. Sergeeva, A.A. Bogomolov, A.V. Solnyshkin, N.V. Komarov, S.A. Kukushkin, D.M. Krasovitsky, A.L. Dudin, D.A. Kiselev, S.V. Ksenich, S.V. Senkevich, E.Yu. Kaptelov I.P. Pronin. Ferroelectrics 477, 121 (2015).

[20] С.А. Кукушкин, А.В. Осипов, О.Н. Сергеева, Д.А. Киселев, А.А. Богомолов, А.В. Солнышкин, Е.Ю. Каптелов, С.В. Сенкевич, И.П. Пронин. ФТТ 58, 937 (2016).

[21] V.N. Bessolov, E.V. Konenkova, S.A. Kukushkin, A.V. Osipov, S.N. Rodin. Rev. Adv. Mater. Sci. 38, 75 (2014).

[22] K.Ch. Chiu, T.H. Yang, J.M. Wu. Nanotechnology 24, 225602 (2013).

[23] H. Shin, J.-T. Song. J. Korean Phys. Soc. 56, 580 (2010).

[24] B.J. Rodriguez, A. Gruverman, A.I. Kingon, R.J. Nemanich. J. Cryst. Growth 246, 252 (2002).

Редактор К.В. Емиев 